\title{
Bi-Level Positive Airway Pressure for Non-invasive Respiratory Support of Foals
}

\author{
Sharanne L. Raidal*, Chee Sum Melanie Catanchin, Lexi Burgmeestre and Chris T. Quinn \\ School of Animal and Veterinary Sciences, Charles Sturt University, Wagga Wagga, NSW, Australia
}

Respiratory insufficiency and pulmonary health are important considerations in equine neonatal care. As the majority of foals are bred for athletic pursuits, strategies for respiratory support of compromised foals are of particular importance. The administration of supplementary oxygen is readily implemented in equine practice settings, but does not address respiratory insufficiency due to inadequate ventilation and is no longer considered optimal care for hypoxia in critical care settings. Non-invasive ventilatory strategies including continuous or bi-level positive airway pressure are effective in human and veterinary studies, and may offer improved respiratory support in equine clinical

Edited by:

Tanmoy Rana

West Bengal University of Animal and

Fishery Sciences, India

Reviewed by:

Dharm Singh Meena,

Post-Graduate Institute of Veterinary

Education and Research

(PGIVER), India

Pds Raghuvanshi,

Chhattisgarh Kamdhenu

Vishwavidyalaya, India

*Correspondence:

Sharanne L. Raidal

sraidal@csu.edu.au

Specialty section:

This article was submitted to

Veterinary Emergency and Critical

Care Medicine,

a section of the journal

Frontiers in Veterinary Science

Received: 15 July 2021

Accepted: 27 August 2021

Published: 29 September 2021

Citation:

Raidal SL, Catanchin CSM, Burgmeestre L and Quinn CT (2021) Bi-Level Positive Airway Pressure for Non-invasive Respiratory Support of Foals. Front. Vet. Sci. 8:741720.

doi: 10.3389/fvets.2021.741720 practice. The current study was conducted to investigate the use of a commercial bi-level positive airway pressure (BiPAP) ventilator, designed for home care of people with obstructive respiratory conditions, for respiratory support of healthy foals with pharmacologically induced respiratory insufficiency. A two sequence (administration of supplementary oxygen with, or without, BiPAP), two phase, cross-over experimental design was used in a prospective study with six foals. Gas exchange and mechanics of breathing (increased tidal volume, decreased respiratory rate and increased peak inspiratory flow) were improved during BiPAP relative to administration of supplementary oxygen alone or prior studies using continuous positive airway pressure, but modest hypercapnia was observed. Clinical observations, pulse oximetry and monitoring of expired carbon dioxide was of limited benefit in identification of foals responding inappropriately to BiPAP, and improved methods to assess and monitor respiratory function are required in foals.

Keywords: non-invasive ventilation (NIV), equine critical care, neonatology, equine respiratory physiology, respiratory insufficiency

\section{INTRODUCTION}

Respiratory disease has long been recognized as of considerable economic importance in newborn foals (1), and as an important cause of morbidity and death in neonates presented for veterinary care $(2,3)$. Optimal respiratory support is highly desirable to optimize survival and preserve respiratory function in animals bred largely for their athletic potential.

The use of non-invasive ventilation (NIV) is now widely regarded as the most effective approach for respiratory support of human neonates $(4,5)$, with continuous positive airway pressure (CPAP) shown to reduce the number of preterm infants requiring admission to neonatal intensive care (6), and to decrease the risk of bronchopulmonary dysplasia or death in neonates requiring 
respiratory support (7). The technique involves the delivery of a constant positive (greater than atmospheric) pressure to the airway and preserves spontaneous respiration. The physiological effects are complex and likely to vary depending on the underlying pathology (8), but benefits have been attributed to increased functional residual capacity, decreased work of breathing and reduced airway resistance (4). Previous studies have demonstrated that CPAP is associated with improved respiratory function in a number of veterinary species (912). CPAP has recently been shown to improve gas exchange in healthy foals with pharmacologically induced respiratory suppression (13), however hypercapnia was observed in treated foals in this study, and has been observed previously in anesthetized horses during $\operatorname{CPAP}(10,11,14)$.

$\mathrm{Bi}$-level positive airway pressure (BiPAP) is also recognized for the management of respiratory insufficiency in human neonates, and has demonstrated improved treatment outcomes in preterm human neonates in comparison to $\operatorname{CPAP}(15,16)$. By using lower expiratory pressures, BiPAP promises improved expiratory function and is recommended for management of conditions associated with hypercapnia, such as chronic obstructive airway disease or asthma (17-19). In human patients with obstructive airway conditions, expiratory airflow limitations may cause increased $\mathrm{PaCO}_{2}$ due to overdistension of alveoli and consequent increased alveolar dead space (20-23), an effect which has been termed dynamic hyperinflation (24).

Whereas, human neonates exhale passively (25), both inspiration and expiration are active processes, requiring muscular effort, in foals (26). Foals might therefore be predisposed to expiratory flow limitations and retention of $\mathrm{CO}_{2}$ if active breathing strategies are unable to overcome expiratory pressures during CPAP, and the technique might be thus be associated increased intrinsic positive end-expiratory pressure (PEEPi) and alveolar overdistension, and hence predispose to hypercapnia. Lower expiratory pressures during BiPAP might be expected to facilitate expiration and ameliorate this effect. The current study was undertaken to determine whether a commercially available bi-level respiratory device, available for the home care of people with respiratory disease, might represent a ventilatory support strategy in healthy foals with pharmacologically induced respiratory insufficiency. We hypothesized that BiPAP would be associated with improved respiratory function, and with less $\mathrm{CO}_{2}$ retention, than observed previously during CPAP (13). Intentionally, the study was designed to evaluate low cost intervention and monitoring strategies that might be safely implemented in equine practice or on farm.

\section{MATERIALS AND METHODS}

\section{Animals}

Six healthy foals (two colts, four fillies) of mean age 47.7 days (range 44-52 days) and mean body weight $111.2 \mathrm{~kg}$ (range 86$125 \mathrm{~kg}$ ) were available for the current study. All foals were Connemara cross breeding and were normal on veterinary examination at the time of recruitment into the study, and prior to each intervention.

\section{Experimental Design}

A randomized crossover design was used with the first treatment assigned (either BiPAP or mask $\mathrm{O}_{2}$ ) determined by coin toss (Supplementary Table S1). Treatment order was reversed for the next data collection day for each foal. A cross-over design was selected for the interventional study to further increase statistical power and to control for individual differences and possible effects attributable to treatment order. The interval between intervention periods ranged from 3 to 6 days, and the cross over design included treatment in both left (Phase 1) and right lateral recumbency (Phase 2) for each foal. The study protocol was approved by the Charles Sturt University Animal Care and Ethics Committee (ACEC A18044).

\section{Sedation and Sampling Protocol}

Prior to each study, foals were manually restrained for veterinary examination and collection of baseline arterial blood samples from the carotid artery (T-1). Briefly, the right carotid artery was palpated in the distal cervical region; the skin was swabbed with $70 \%$ ethanol, and the jugular vein proximal to the injection site was occluded. A $23 \mathrm{G}, 32 \mathrm{~mm}$ needle was introduced into the carotid artery at a $45^{\circ}$ angle and blood collected directly into a pre-heparinised syringe (BD Heparinised Syringes, Becton Dickinson, North Ryde, Australia). Pressure was applied to the arteriopuncture site for $1-2 \mathrm{~min}$. A $16 \mathrm{G}, 89 \mathrm{~mm}$ catheter (Terumo Surflo, Macquarie Park, Australia) was aseptically placed in the jugular vein of each foal and a baseline sample of venous blood was collected directly into pre-heparinised syringes from the catheter for each foal prior to sedation. Blood gas analysis (GEM Premier, Model 3500; Abacus ALS, Macquarie Park, Australia) was performed on anaerobically collected samples to determine partial pressures of oxygen and carbon dioxide $\left(\mathrm{PaO}_{2}\right.$ and $\mathrm{PaCO}_{2}$, respectively), hemoglobin saturation $\left(\mathrm{sO}_{2}\right)$ and $\mathrm{pH}$. Spirometry was performed on standing foals as previously described (13) by application of a large veterinary anesthesia mask (SurgiVet large canine mask, product number 32393B1; Sound Veterinary Equipment, Rowville, Australia) placed on the foal's muzzle in such a way as to exclude air leaks and to minimize dead space, but not prevent opening of the nares. A respiratory flow head (Respiratory Flow Head 300 L, MLT300L, ADInstruments, Bella Vista, Australia) and gas sampling port were connected to the anesthesia mask. Dead space of this apparatus was $60 \mathrm{~mL}$ (measured by water displacement). Data were collected for up to $60 \mathrm{~s}$ (sufficient to ensure 10 artifact free breath cycles) in unsedated foals, and analyzed using PowerLab 4/25, Gas Analyser ML206, and LabChart 8 software (ADInstruments, Bella Vista, Australia). Tidal volume $(\mathrm{Vt})$, peak inspiratory and peak expiratory air flow (PIF, PEF), and the duration of inspiratory (Ti) and expiratory (Te) phases were determined by post-sampling analysis of six consecutive and artifact free breath cycles representative of tidal breathing. Spirometry, inspired and expired gas analysis $\left(\mathrm{FiO}_{2}, \mathrm{FeO}_{2}\right.$, $\mathrm{FiCO}_{2}$, and $\mathrm{FeCO}_{2}$ ) were performed following calibration of the spirometer pod using a using a seven liter certified calibration syringe (Hans Rudolph Incorporated, Shawnee, Kansas, USA) and the gas analyser was calibrated using a two point calibration of room air $\left(20.9 \% \mathrm{O}_{2}, 0.04 \% \mathrm{CO}_{2}\right)$ and Carbogen $\left(95 \% \mathrm{O}_{2}, 5 \%\right.$ 
$\mathrm{CO}_{2}$; BOC Gas, Wagga Wagga, Australia). Pulse oximetry $\left(\mathrm{SpO}_{2}\right)$ was performed, when possible, with a transmission probe (Avant 2120, Nonin Medical Inc., Plymouth, MN, USA; distributed by Proact Medical Systems, Port Macquarie, NSW, Australia) placed on the tongue. Results were recorded when the signal was constant over $2 \mathrm{~min}$, pulse rate matched heart rate, and pulse strength was satisfactory. Pulse oximetry was not possible when the anesthetic mask was in place.

Diazepam $(0.2 \mathrm{mg} / \mathrm{kg})$ was administered via the intravenous catheter, and spirometry (T0) was repeated $5 \mathrm{~min}$ following treatment. Fentanyl (5 $\mu \mathrm{g} / \mathrm{kg}$; Hospira, Melbourne, Australia) and xylazine $(0.2 \mathrm{mg} / \mathrm{kg}$; Illium Veterinary Products, Glendenning, Australia) were then administered via the jugular catheter, and foals were placed in lateral recumbency. A $22 \mathrm{G}$, $25 \mathrm{~mm}$ polyurethane catheter (Surflo, Terumo Australia Pty Ltd, Macquarie Park, Australia) was placed aseptically into the lateral metatarsal artery, and an arterial blood sample collected anaerobically (T0). Foals were monitored by determination of cardinal signs (HR, RR, temperature, MAP), arterial blood gases $\left(\mathrm{PaO}_{2}, \mathrm{PaCO}_{2}, \mathrm{sO}_{2}, \mathrm{pH}\right)$, spirometry and inspired/expired gas analysis. Spirometry data were collected over $20-40 \mathrm{~s}$, after collection of arterial blood samples, to minimize any effects attributable to apparatus dead space. Respiratory suppression was then induced by continuous infusion of fentanyl $(0.005$ $\mathrm{mg} / \mathrm{kg} / \mathrm{h})$ and xylazine $(0.7 \mathrm{mg} / \mathrm{kg} / \mathrm{h})$ in $0.9 \%$ sodium chloride delivered via syringe pump (Alaris IMED Gemini PC-1 infusion pump; VetQuip Pty Ltd, Erskine Park, NSW), commencing immediately after collection of T0 samples. Samples were again collected after $10 \mathrm{~min}$ spontaneous respiration (10 min following commencement of the fentanyl-xylazine CRI, T1), and respiratory support (BiPAP or $\mathrm{O}_{2}$ supplementation) was commenced $10 \mathrm{~min}$ following collection of $\mathrm{T} 1$ samples. The treatment and sample schedule is shown in Table $\mathbf{1}$.

\section{BiPAP and $\mathrm{O}_{2}$ Supplementation}

Respiratory support (BiPAP or $\mathrm{O}_{2}$ supplementation) was delivered via the large veterinary anesthesia mask used for spirometry measurements. The mask was connected to a vented non-rebreathing elbow valve (Oracle 2 Vented Non-rebreathing Valve, 400HC206, Fisher and Paykel Healthcare, Nunawading, Victoria, Australia), hence to a commercial, bi-level pressure support ventilator specifically designed for non-invasive mask ventilation (VPAPTM III ST, ResMed Ltd., Bella Vista, NSW) via standard air tubing (ResMed Ltd., Bella Vista, NSW) of two meter length (Supplementary Figure S1). Based on previous findings, a minimum respiratory rate (RR) of $15 \mathrm{bpm}$ was set on the ventilator, such that a breath would be initiated if spontaneous ventilation fell below this rate. Inspiratory pressure (IPAP) was set at $15 \mathrm{cmH} 2 \mathrm{O}$, and expiratory pressure (EPAP) was set at $5 \mathrm{cmH} 2 \mathrm{O}$. The maximum duration of IPAP was $1.2 \mathrm{~s}$ to prevent prolonged inspiration, minimum duration of IPAP set at $0.5 \mathrm{~s}$ to prevent false triggering, and the I:E ratio was $1: 2.3$. Oxygen $(8 \mathrm{~L} / \mathrm{min})$ was delivered into the system between the non-rebreathing valve and the ventilator tubing, as shown (Supplementary Figure S1). A pressure manometer (Advanced Anesthetic Services, Gladesville, Australia) was connected to the BiPAP ventilator to enable circuit pressure monitoring. Spirometry and gas sampling were performed by inserting the respiratory flow head and gas sampling port between the oneway valve and mask, as shown in Supplementary Figure S1, at the end of each respiratory intervention and after collection of arterial blood samples. Temperature, HR, RR, and MAP were recorded over the final $2 \mathrm{~min}$ of each respiratory intervention. Pulse oximetry $\left(\mathrm{SpO}_{2}\right)$ could not be performed during mask administration of $\mathrm{O}_{2}$ or BiPAP because the transmission probe could not be placed on the tongue.

\section{Statistical Methods}

Power analysis from previous studies demonstrated that a sample size of six foals would discriminate differences in $\mathrm{PaO}_{2}$ and $\mathrm{PaCO}_{2}$ of 15 and $5 \mathrm{mmHg}$, respectively, with a power $>0.80$ and $\alpha=0.05$. Data were tested for normality by the ShapiroWilks test and explored using appropriate descriptive statistics. The effect of replicate (Phase 1 or Phase 2$)$ and sequence $\left(\mathrm{O}_{2}\right.$ or

TABLE 1 | Treatment and sampling schedule.

\begin{tabular}{|c|c|c|c|c|c|c|c|c|c|}
\hline \multirow[t]{2}{*}{ Time } & & \multirow[t]{2}{*}{ Position } & \multirow[t]{2}{*}{ Sedation } & \multirow[t]{2}{*}{ Respiratory support } & \multicolumn{5}{|c|}{ Samples } \\
\hline & & & & & Spiro & ABG & TPR & MAP & $\mathrm{SpO}_{2}$ \\
\hline $\mathrm{T}-1$ & 0 min & Standing & Nil & Nil & $\checkmark$ & $\checkmark$ & $\checkmark$ & & \\
\hline \multirow[t]{2}{*}{ TO } & $10 \mathrm{~min}$ & Standing & Diazepam 0.2 mg/kg & Nil & $\checkmark$ & & $\checkmark$ & & \\
\hline & & Lateral & Fentanyl $5 \mu \mathrm{g} / \mathrm{kg}$ + xylazine 0.02 mg/kg; commence CRI & $\mathrm{Nil}$ & & $\checkmark$ & & $\checkmark$ & $\checkmark$ \\
\hline $\mathrm{T} 1$ & $20 \mathrm{~min}$ & Lateral & CRI & Nil & $\checkmark$ & $\checkmark$ & $\checkmark$ & $\checkmark$ & $\checkmark$ \\
\hline $\mathrm{T} 2$ & $30 \min$ & Lateral & $\mathrm{CRI}$ & $\mathrm{O}_{2}$ or $\mathrm{BiPAP}$ & $\checkmark$ & $\checkmark$ & $\checkmark$ & $\checkmark$ & \\
\hline T3 & $40 \mathrm{~min}$ & Lateral & $\mathrm{CRI}$ & Nil & $\checkmark$ & $\checkmark$ & $\checkmark$ & $\checkmark$ & $\checkmark$ \\
\hline $\mathrm{T} 4$ & $50 \mathrm{~min}$ & Lateral & CRI & BiPAP or $\mathrm{O}_{2}$ & $\checkmark$ & $\checkmark$ & $\checkmark$ & $\checkmark$ & \\
\hline T5 & $60 \mathrm{~min}$ & Lateral & End CRI & Nil & $\checkmark$ & $\checkmark$ & $\checkmark$ & $\checkmark$ & $\checkmark$ \\
\hline
\end{tabular}

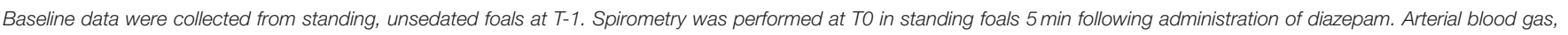

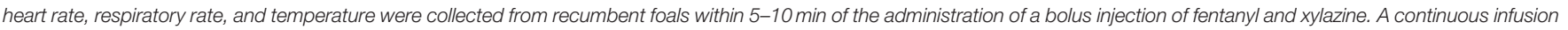

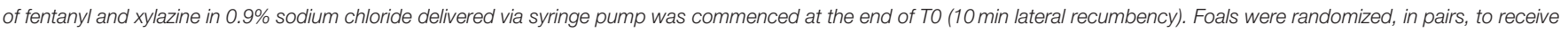

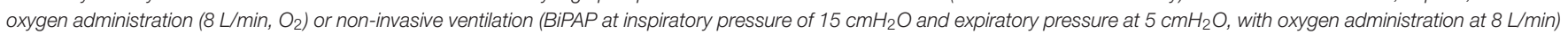

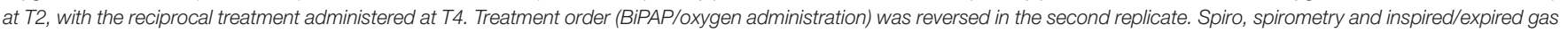
analysis; ABG, arterial blood gas; TPR, temperature, heart (pulse) rate, respiratory rate, and mean arterial pressure; $\mathrm{SpO} \mathrm{O}_{2}$, pulse oximetry. 
BiPAP at T2 with reciprocal treatment at T4) were evaluated by fitting separate mixed effects models using restricted maximum likelihood (REML) with time and replicate or sequence as random factors and foal as a fixed factor. In the absence of significant replicate or sequence effects, treatment effects (BiPAP vs. $\mathrm{O}_{2}$ ) were determined by mixed effects models with time as a random factor and subject as a fixed factor and post-hoc testing by Tukey's method. Non-parametric results were analyzed by Kruskal-Wallis test, with post-hoc testing by Dunn's method. Relationships between $\mathrm{PaO}_{2}, \mathrm{sO}_{2}$, and pulse oximetry $\left(\mathrm{SpO}_{2}\right)$, and between maximum $\mathrm{CO}_{2}$ in expired air $\left(\mathrm{CO}_{2} \max \right)$ and $\mathrm{PaCO}_{2}$, were explored using Pearson's correlation; Bland-Altman analyses were used to assess agreement between these indices. Unless specifically stated, data satisfied criteria for normality and parametric tests were used. Significance was accepted as $P<$ 0.05 and all analyses were performed using Graph Pad Prism 8.4.3 for Windows (GraphPad Software, San Diego, California USA, www.graphpad.com).

\section{RESULTS}

No effects attributable to replicate were observed for any parameter. Effects associated with sequence (BiPAP or supplementary $\mathrm{O}_{2}$ at $\mathrm{T} 2$ ) are shown in Supplementary Materials. Heart and respiratory rates were highest in unsedated foals, and temperature decreased significantly throughout the study period (from 38.5 to $37.8^{\circ} \mathrm{C}$ ). Mean arterial pressure did not change associated with time or treatment (Supplementary Figure S2).

Oxygenation $\left(\mathrm{PaO}_{2}\right)$ was greater in unsedated foals $(\mathrm{T}-1)$ than observed in sedated foals at T0 $(P=0.002)$ or T1 $(P=0.004$, Figure 1). The administration of supplementary oxygen alone or with BiPAP was associated with significantly increased $\mathrm{PaO}_{2}$ in comparison to results at all other sampling times (all $P<$ 0.001), and results following BiPAP were significantly greater than after $\mathrm{O}_{2}$ administration $(P=0.021)$. Arterial $\mathrm{CO}_{2}\left(\mathrm{PaCO}_{2}\right)$ results were not normally distributed and were resistant to transformation. Values were lowest in unsedated foals at T-1, and differences at this time and at T0 were significant when compared to results following administration of supplementary $\mathrm{O}_{2}$ and following BiPAP (all $P<0.001$, Figure 1); differences at other times were not significant. Results following supplementary $\mathrm{O}_{2}$ administration were not significantly different to those obtained after BiPAP $(P=1.000)$. Hypercapnia $\left(\mathrm{PaCO}_{2}>60\right.$ $\mathrm{mHg}$ ) was observed for two foals (F8 and F9) following $\mathrm{O}_{2}$ administration (60 and $66 \mathrm{mmHg}$, respectively), and following BiPAP on both occasions for F9 (60 and $68 \mathrm{mmHg}$ ). Changes to blood $\mathrm{pH}$ mirrored changes to $\mathrm{PaCO}_{2}$ and effects on lactate and blood glucose treatment attributable to treatment were not observed (Supplementary Figure S3). Blood glucose concentrations increased across all sampling times (likely due to administration of xylazine), with results at T3 $(P=0.013)$ and T5 $(P=0.008)$ significantly higher than at T0, as were results during $\mathrm{O}_{2}(P=0.008)$ and $\operatorname{BiPAP}(P=0.016$, data not shown $)$.

Significant time-sequence interactions were observed for spirometry variables including respiratory rate during spirometry (RRs), tidal volume $(\mathrm{Vt})$, inspiratory time $(\mathrm{Ti})$, expiratory time (Te), and peak inspiratory flow (PIF) (Supplementary Figure S4); BiPAP was associated with significantly lower RR $(P=0.014)$ and significantly longer inspiratory $(P<0.001)$ and expiratory $(P=0.020)$ times at T2 than observed following $\mathrm{O}_{2}$ administration at this time. Differences at other time points were not significant, so data have been combined for analysis of treatment effects. Sedation with diazepam at T0 was associated with a significant decrease in RRs relative to each other sampling times (Figure 2), except following BiPAP (all $P<0.050$ ). Respiratory rate (RRs) during BiPAP was lower than was observed at T1 $(P=0.041)$, T3 $(P=0.012)$ or following $\mathrm{O}_{2}$ administration $(P<0.001)$. Tidal volume $(\mathrm{Vt})$ was greatest in standing foals following diazepam sedation (T0) and values observed at this time and in unsedated foals at $\mathrm{T}-1$ were significantly greater than observed in recumbent foals with the
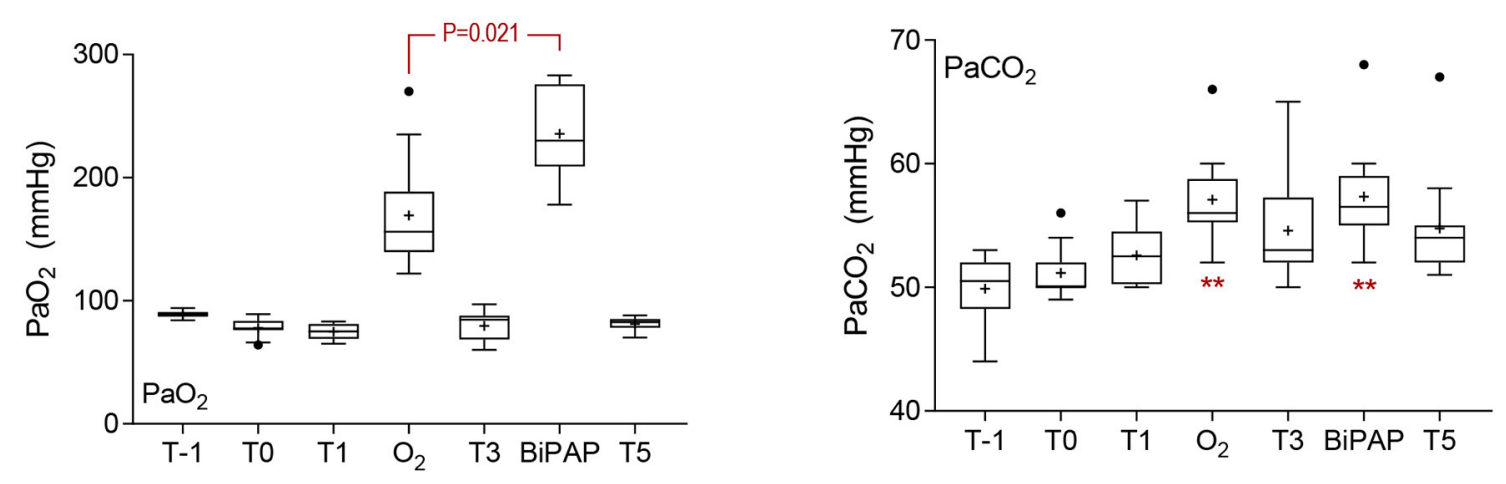

FIGURE 1 | Blood gas results. Sedation was associated with a significant decrease in $\mathrm{PaO}_{2}$ at T0 $(P=0.002)$ and T1 $(P=0.004)$. The administration of supplementary oxygen by mask $\left(\mathrm{O}_{2}\right)$ or during bi-level positive airway pressure ventilation $(\mathrm{BiPAP})$ was associated with a significant increase in $\mathrm{PaO}$ (both $\left.P<0.001\right)$, and results following BiPAP were significantly greater than following $\mathrm{O}_{2}$, as indicated. Results for arterial $\mathrm{CO}_{2}$ pressures were not normally distributed, and were resistant to transformation. Results following $\mathrm{O}_{2}$ and BiPAP were significantly greater than results at $\mathrm{T}-1$ and $\mathrm{TO}$, as shown (**P $<0.001$ ), following analysis by Kruskal Wallis test. Differences in $\mathrm{PaCO}_{2}$ were not different following $\mathrm{O}_{2}$ or BiPAP $(P=1.000)$. Data are shown as mean $(+)$, median (horizontal line), and quartiles (box), with whiskers and outliers determined by Tukey method. 

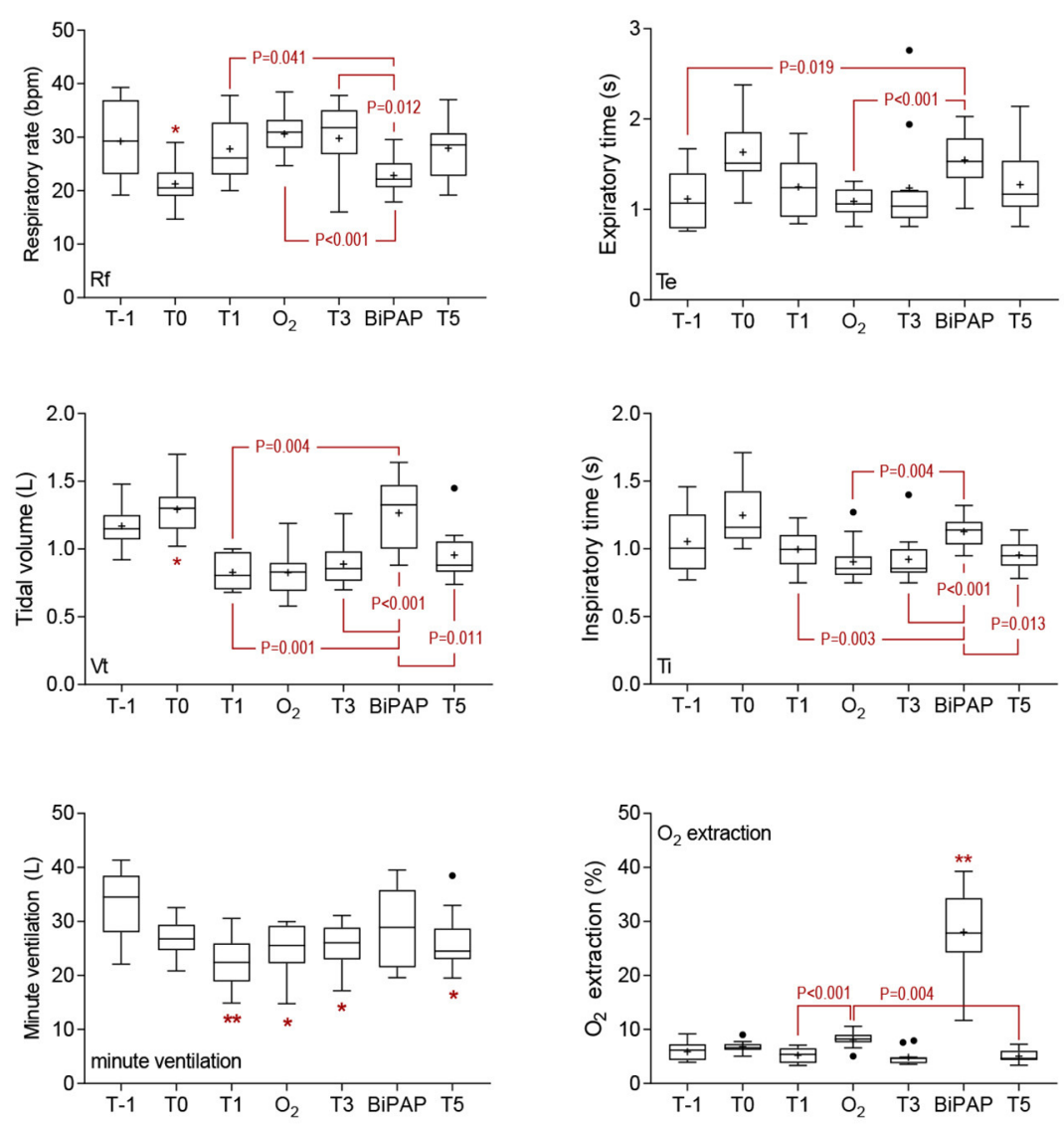
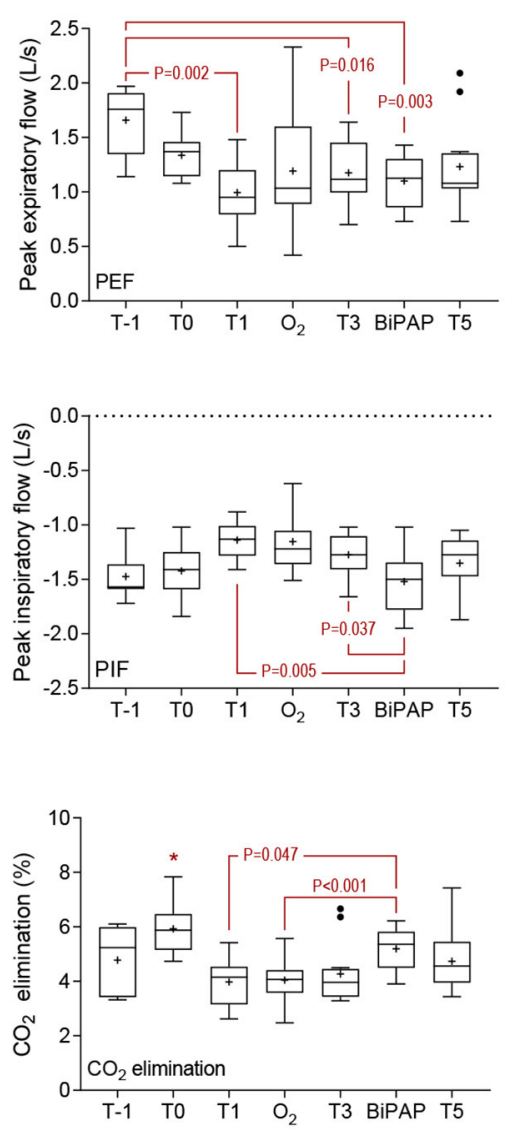

FIGURE 2 | Spirometry and gas exchange results. Sedation was associated with a significant decrease in respiratory rate during spirometry (RRs) at T0, and this effect was significant $(P<0.05)$ in comparison with results at all other time points except during bi-level positive airway pressure ventilation (BiPAP). Effects on tidal volume (Vt) reciprocated those observed on RRs, with differences again observed at TO $(P<0.05$ when compared to other sampling points with the exception of during BiPAP). Minute ventilation was greatest in standing, unsedated foals $(\mathrm{T}-1)$, and significant decreases were observed at all other sampling points $\left({ }^{\star} P<0.05\right.$ and ${ }^{* \star} P<0.01$ ) except during BiPAP. Inspiratory (Ti) and expiratory (Te) times were longest in standing foals following sedation with diazepam (T0), but significant effects were observed only in comparison with T5 $(P=0.020)$ for Ti. For Te, comparisons between T0 and T-1 $(P=0.008), \mathrm{O}_{2}(P=0.006)$, and T5 $(P=0.012)$ were significant. Significant time effects on peak expiratory (PEF) and inspiratory (PIF) flows are shown. The administration of BiPAP was associated with greater $\mathrm{O}_{2}$ extraction than observed at any other time (**, all $P<0.01$ ). Oxygen extraction was also greater during mask $\mathrm{O}_{2}$ administration, as shown, and at T0 (standing foals following administration of diazepam) than at T3 $(P=0.046)$ or T5 $(P<0.001)$. The elimination of $\mathrm{CO}_{2}$ was greatest at T0 than at any other time, except following BiPAP $\left(^{*}\right.$, all $\left.P<0.05\right)$. Differences between effects observed following BiPAP administration and at other times are shown. Data are shown as mean ( + ), median (horizontal line) and quartiles (box), with whiskers and outliers determined by Tukey method.

exception of during BiPAP (all $P<0.05$ ). The administration of BiPAP was associated with significantly greater $\mathrm{Vt}$ than was observed at T1 $(P=0.001)$, T3 $(P<0.001)$, T5 $(P=0.011)$ and during $\mathrm{O}_{2}$ administration $(P<0.001)$, and effects were more pronounced at T2 than at T4 (Supplementary Figure S4). Recumbency was associated with a significant reduction in minute ventilation relative to results from standing, unsedated foals (T-1), but this effect was not observed during BiPAP (Figure 2).

Significant effects were observed for both inspiratory and expiratory time, reflective of changes observed in RRs (Figure 2), but there was no effect on I:E ratio (data not shown). Peak inspiratory flow was greatest during $\operatorname{BiPAP}(-1.52 \mathrm{~L} / \mathrm{s})$, and significant effects were observed compared to values obtained at T1 $(P=0.005)$ and T3 $(P=0.037)$. Expiratory flows were greatest in unsedated foals (T-1), and significant differences were observed at T1 $(P=0.002), \mathrm{T} 3(P=0.016)$, and during BiPAP $(P$ $=0.003$ ).

Time and sequence effects were observed for data derived from analysis of inspired/expired gas composition due to differences following $\mathrm{O}_{2}$ administration or BiPAP at T2 (Supplementary Figure S5). Differences at other time points were not significant, so data have been combined for analysis of treatment effects. As expected, the administration of supplementary $\mathrm{O}_{2}$ was associated with an increased $\mathrm{FiO}_{2}$ during both mask supplementation and $\mathrm{BiPAP}$, compared to $\mathrm{FiO}_{2}$ when breathing room air (all $P<0.001$ ), and values were significantly greater during BiPAP than during administration of $\mathrm{O}_{2}$ only $(P=0.004)$. Oxygen concentrations in expired air were also greater following the administration of supplementary 
$\mathrm{O}_{2}$, but differences were not observed between mask $\mathrm{O}_{2}$ administration and BiPAP $(P=0.172)$. Oxygen extraction was much greater during BiPAP than at all other time points (all $P<0.005)$, including during $\mathrm{O}_{2}$ administration $(P<0.001$, Figure 2). Oxygen extraction was also greater during mask $\mathrm{O}_{2}$ administration than at T1 $(P<0.001)$ or T5 $(P=0.004)$, and in standing foals at T0 relative to T3 $(P=0.046)$ and T5 $(P<0.001)$. Maximum concentrations of $\mathrm{CO}_{2}\left(\mathrm{CO}_{2} \mathrm{max}\right)$ were observed at T0 in standing foals following administration of diazepam and observed differences were significant in comparison with results at T-1 $(P=0.016)$, T1 $(P=0.0003)$, T3 $(P=0.026)$, T5 $(P=0.0002)$, and following $\mathrm{O}_{2}$ administration $(P=0.031)$. Results after BiPAP were significantly greater than following $\mathrm{O}_{2}$ administration $(P=0.047)$. Minimum concentrations of $\mathrm{CO}_{2}$ were observed during BiPAP, and differences were significant in comparison with T3 $(P=0.021)$ and T5 $(P=0.013)$. The elimination of $\mathrm{CO}_{2}$ was greatest at $\mathrm{T} 0$ in diazepam sedated foals, with significant differences observed between results at $\mathrm{T} 0$ and all other sampling points, with the exception of BiPAP (all $P<0.030$, Figure 2). Results observed following BiPAP were significantly greater than observed at T1 $(P=0.047)$ or following $\mathrm{O}_{2}$ administration $(P=0.004)$.

Paired results for pulse oximetry $\left(\mathrm{SpO}_{2}\right)$ and hemoglobin saturation determined by blood gas analysis $\left(\mathrm{sO}_{2}\right)$ were available for 47 data sets from the current study. $\mathrm{SpO}_{2}$ results correlated significantly with $\mathrm{sO}_{2}(r=0.61,95 \% \mathrm{CI} 0.34-0.78, P<0.001)$, but there was poor agreement between these two methods of assessing hemoglobin saturation (Figure 3). Although bias was minimal (1.4\%, standard deviation 5.4\%), the observed limits of agreement were large ( -11.95 to $9.2 \%)$, and increased divergence was observed for results obtained from the most hypoxic foal. Paired results for $\mathrm{CO}_{2} \max$ and $\mathrm{PaCO}_{2}$ were available for 136 data sets (Figure 3). There was poor but significant correlation between results $(r=0.25,95 \%$ CI $0.09-0.40, P=0.003)$, and agreement was poor (bias $14.0 \pm 8.9 \%$ ) with broad limits of agreement ( -3.5 to $31.5 \%)$.

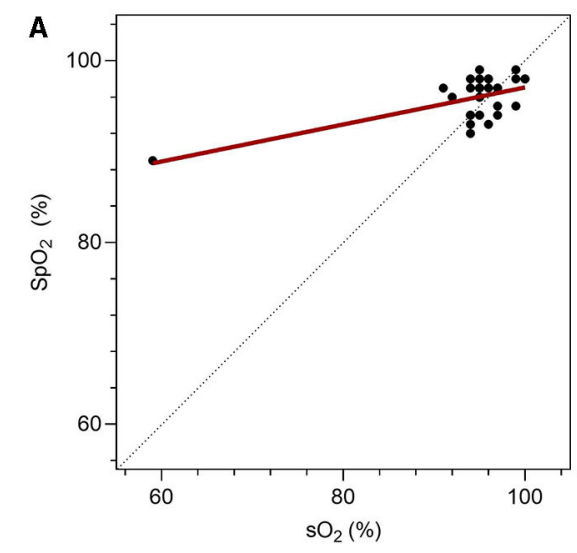

C

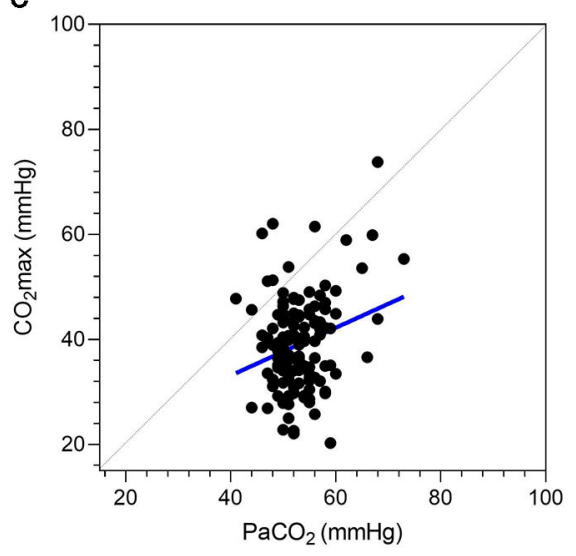

B

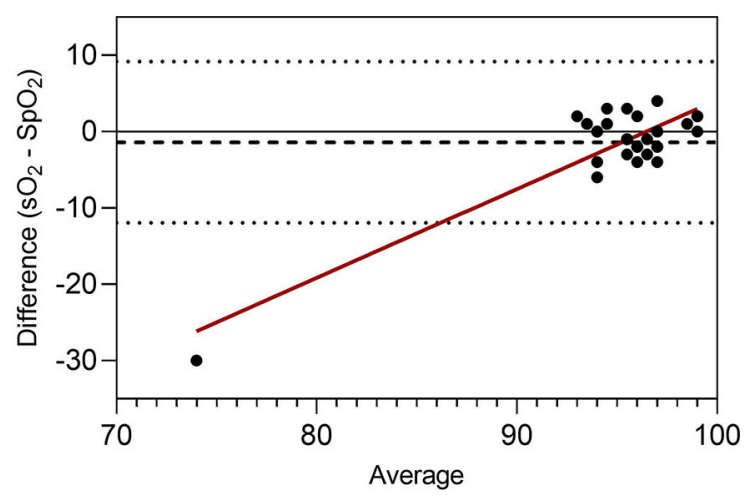

D

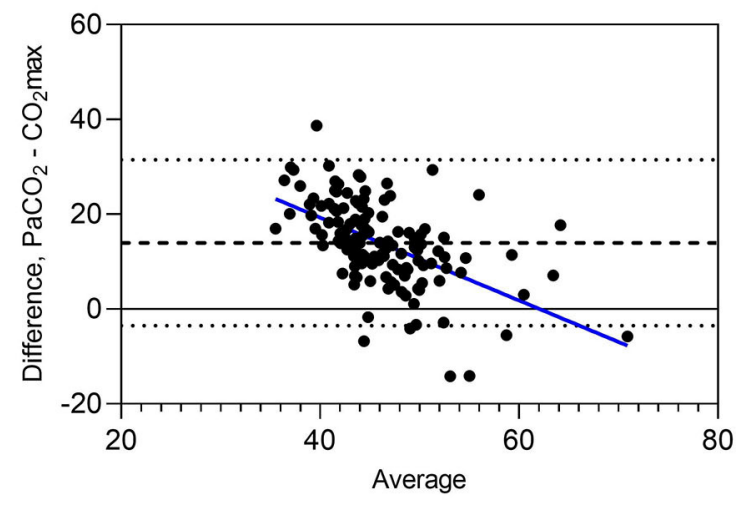

FIGURE 3 | Associations between blood gas results and non-invasive measures of oxygenation (pulse oximetry, $\left.\mathrm{SpO}_{2}\right)$ and carbon dioxide accumulation $\left(\mathrm{CO}_{2}\right.$ max). Results are presented as correlations (A,C), with perfect agreement (unity) shown as a dotted line. Agreement is shown following Bland-Altman analysis (B,D), with the mean difference (dashed line) and limits of agreement (dotted lines) shown. Oxygenation of hemoglobin $\left(\mathrm{sO}_{2}\right)$ and partial pressure of $\mathrm{CO}_{2}\left(\mathrm{PaCO}_{2}\right)$ were determined from blood gas analyses. 


\section{DISCUSSION}

Improved blood oxygenation was observed following BiPAP relative to mask administration of supplementary $\mathrm{O}_{2}$. BiPAP was also associated with decreased RR, increased Vt and increased minute ventilation, suggesting that respiratory mechanics were improved by respiratory support. Increased Vt represents a more efficient ventilation strategy than increased RR, as there is increased alveolar ventilation relative to ventilation of airway dead space, and decreased RR is likely to be associated with decreased work of breathing. Increased inspiratory pressure during BiPAP was associated with increased PIF, and the adverse effects on PEF observed during CPAP in previous studies (13) were not observed in the current study, presumably due to the lower expiratory pressures during BiPAP, relative to CPAP. As expected, increased $\mathrm{FiO}_{2}$ was observed during mask administration of supplementary $\mathrm{O}_{2}$ and during BiPAP, so observed increases in arterial oxygenation likely reflect the steeper diffusion gradient resulting from these changes. Surprisingly, $\mathrm{FiO}_{2}$ was higher during $\mathrm{BiPAP}$ than during $\mathrm{O}_{2}$ administration to foals. This observation was not expected during positive pressure respiratory support, where increased flow is associated with decreased partial pressure of $\mathrm{O}_{2}$ (27).

Increased $\mathrm{PaCO}_{2}$ was observed in foals following both forms of respiratory support, including hypercapnia $\left(\mathrm{PaCO}_{2}>60\right.$ $\mathrm{mmHg}$ ) following $\mathrm{O}_{2}$ administration (two foals) or BiPAP (one foal). Hypercapnia has been reported in response to $\mathrm{O}_{2}$ supplementation in human neonates (28) and foals (13, 29 ), and may be due to reduced respiratory drive, increased metabolic rate, hypoventilation due to sedation or effects of equipment dead space. As the minimum inspired $\mathrm{CO}_{2}$ was greater during the administration of supplementary $\mathrm{O}_{2}$ than during BiPAP, it is likely that mask administration of supplementary $\mathrm{O}_{2}$ in the current study was associated with $\mathrm{CO}_{2}$ retention, a problem that might be avoided by the use of a non-rebreathing valve during BiPAP, or by nasal insufflation of oxygen. This effect was not observed during BiPAP. Despite decreased RR, minute ventilation during BiPAP was the same as observed in standing, unsedated foals in the current study suggesting that BiPAP prevented reduced ventilation associated with sedation and recumbency. However, our hypothesis, that lower expiratory pressures associated with BiPAP and improved expiratory function would ameliorate hypercapnia was not demonstrated. As was observed during CPAP (13), the observed increases in $\mathrm{PaCO}_{2}$ and $\mathrm{pH}$ in the current study were modest, and consistent with current ventilation strategies that accept increased arterial $\mathrm{CO}_{2}$ tension and hypercapnic acidosis ("permissive hypercapnia") as acceptable consequences without adverse effects on outcome $(30,31)$, and with possible therapeutic effects (32). Sedation, and the supraphysiological $\mathrm{PaO}_{2}$ values observed in the current study, might have contributed to the observed hypercapnia.

Although reversed within 10 min of cessation of BiPAP, the observed hypercapnia demonstrates the necessity for close monitoring during the implementation of respiratory support in equine neonates. Evaluation of NIV should consider effects on both oxygenation and carbon dioxide, but the current study demonstrated poor agreement between non-invasive methods of continuous monitoring of $\mathrm{O}_{2}$ saturation and $\mathrm{CO}_{2}$ accumulation. Pulse oximetry has been recommended as an appropriate alternative to invasive sampling for determination of hemoglobin saturation, and previous studies have suggested that placement of transmission or reflectance sensors on the lip or tongue ensures the most reliable assessment of $\mathrm{SaO}_{2}$ in foals (33). However, bias and limits of agreement in that study (33) were similar to those observed in the current study and well-outside accepted standards of care (34). Probe placement on the lip or tongue was not possible during mask administration of respiratory support in the current study, and was not tolerated by unsedated foals. Direct measurement of $\mathrm{PaO}_{2}$ and $\mathrm{sO}_{2}$ by co-oximetry is more accurate than blood gas analysis for determination of oxygenation (35), but both techniques require arterial samples, and neither provides an immediate result or allows for continuous monitoring. Arterial samples can be difficult to obtain in hypovolaemic foals or animals with distal limb oedema, and risks associated with arterial puncture include pain, hemorrhage, arterial injury, aneurism formation, thrombosis, and distal ischaemia. End-tidal $\mathrm{CO}_{2}\left(\mathrm{PETCO}_{2}\right)$ is commonly monitored during anesthesia as an indirect measure of $\mathrm{PaCO}_{2}$. Whilst $\mathrm{PETCO}_{2}$ has been reported as an acceptable technique for monitoring of neonatal foals (34), studies during NIV in people have suggested that, as observed in the current study, the technique was not predictive of $\mathrm{PaCO}_{2}$ or changes in $\mathrm{PaCO}_{2}$ (36). The association between $\mathrm{PETCO}_{2}$ and $\mathrm{PaCO}_{2}$ assumes that the patient exhales fully, and that end-expiratory gases approximate gas composition in the alveoli. This assumption is not valid if, as we have hypothesized, foals are not exhaling completely. For this reason peak expired $\mathrm{CO}_{2}$ concentrations have been termed $\mathrm{FeCO}_{2}$ max in the current study. Alternative techniques to assess ventilatory function, such as volume capnography and electrical impedance tomography (37), offer greater capacity to more accurately assess response to respiratory support.

A number of limitations were noted in the current study. Findings in healthy foals with pharmacologicallyinduced respiratory insufficiency may not be predictive of responses in neonates with spontaneous disease, and characterization of the technique in neonates with spontaneous respiratory disease is required. We were unable to document alveolar ventilation, physiological dead space or PEEPi in the current study, which was designed to evaluate a readily available intervention and monitoring strategies that might be readily implemented in a practice setting. The assessment of non-invasive monitoring was based on a small number of observations, and the data set did not include results from foals with severe hypoxaemia or hypercapnia.

\section{CONCLUSIONS}

Consistent with previous studies evaluating CPAP, BiPAP was an effective respiratory support strategy for healthy foals with pharmacologically induced respiratory insufficiency. BiPAP was associated with increased $\mathrm{PaO}_{2}$, more efficient gas exchange and changes in respiratory mechanics including increased tidal volume, decreased respiratory rate, and increased peak 
inspiratory flow. The technique preserved minute ventilation in the face of reduced ventilation observed at other times associated with sedation and recumbency, but was associated with modest increase in $\mathrm{PaCO}_{2}$. As in previous studies, the use of a commercially available ventilator intended for at-home care of adults with chronic obstructive respiratory conditions or sleep apnoea represents an available and potentially cost effective option for use in equine practice, although there is a need for careful and frequent monitoring of patient oxygenation and ventilation (carbon dioxide elimination) during NIV. Our results suggest that monitoring of alveolar ventilation, pressurevolume curves, and PEEPi might be important for effective NIV of foals and to better characterize the response of foals to respiratory support. The use of lower expiratory pressures in the current study did not prevent hypercapnia, and increases in $\mathrm{PaCO}_{2}$ observed in the current study were similar to those observed previously during CPAP in healthy foals. Observed effects on $\mathrm{PaCO}_{2}$ were rapidly reversed and predominantly within acceptable bounds for permissive hypercapnia. Although not a primary objective of the current study, our results suggested the non-invasive monitoring approaches used in this study were not reliable, and techniques are needed for more accurate, non-invasive assessment of respiratory function in foals during NIV.

\section{DATA AVAILABILITY STATEMENT}

The raw data supporting the conclusions of this article will be made available by the authors, without undue reservation.

\section{ETHICS STATEMENT}

The animal study was reviewed and approved by Charles Sturt University Animal Care and Ethics Committee (ACEC A18044).

\section{REFERENCES}

1. Kosch PC, Koterba AM, Coons TJ, Webb AI. Developments in management of the newborn foal in respiratory distress 1: evaluation. Equine Vet J. (1984) 16:312-8. doi: 10.1111/j.2042-3306.1984.tb01934.x

2. Raidal SL, Hughes KJ, Eastwell B, Noble N, Lievaart J. Prevalence and performance effects of neonatal disease in Thoroughbred and Standardbred foals in South-Eastern Australia. Aust Vet J. (2021) 99:15262. doi: 10.1111/avj.13056

3. Koterba AM, Brewer BD, Tarplee FA. Clinical and clinicopathological characteristics of the septicaemic neonatal foal: review of 38 cases. Equine Vet J. (1984) 16:376-82. doi: 10.1111/j.2042-3306.1984.tb01950.x

4. de Winter J, deVries M, Zimmermann L. Clinical practice: noninvasive respiratory support in newborns. Eur J Pediatr. (2010) 169:777-82. doi: 10.1007/s00431-010-1159-x

5. Hussain WA, Marks JD. Approaches to noninvasive respiratory support in preterm infants: from CPAP to NAVA. NeoReviews. (2019) 20:e21321. doi: 10.1542/neo.20-4-e213

6. Bedwell S, Leasure AR, Gibson TL. Interventions for the management of respiratory distress in late preterm and term infants experiencing delayed respiratory transition: a systematic review. Dimens Crit Care Nurs. (2019) 38:192-200. doi: 10.1097/DCC.0000000000000365

7. Schmölzer GM, Kumar M, Pichler G, Aziz K, O’Reilly M, Cheung PY. Non-invasive versus invasive respiratory support in preterm

\section{AUTHOR CONTRIBUTIONS}

All authors contributed to experimental design and conduct of experimental procedures. SR and LB contributed to data analysis and early manuscript drafts, with editing and correction by all authors.

\section{FUNDING}

This study was funded by AgriFutures Australia (PRJ-011159). A contribution towards costs of publication was received from Charles Sturt University's Tri-Faculty Open Access Publication Scheme.

\section{ACKNOWLEDGMENTS}

Numerous veterinary and equine science students assisted with restraint and care of foals (and their dams) including Cathrine Borgen-Nielsen, Tegan Davis, Philippa Kellett, and Stacey Walker. Special thanks go to Equine Centre staff at CSU for their dedicated and ongoing care of mares and foals, and to Jaymie Loy and Equine Science reproduction students for their care of periparturient mares and foals. ResMed Pty Ltd donated bi-level positive airway (BiPAP) ventilators used in this study, and Jeff Armistead provided technical advice. This project was completed in partial fulfillment of Veterinary Honours for Lexi Burgemeestre.

\section{SUPPLEMENTARY MATERIAL}

The Supplementary Material for this article can be found online at: https://www.frontiersin.org/articles/10.3389/fvets. 2021.741720/full\#supplementary-material infants at birth: systematic review and meta-analysis. Br Med J. (2013) 347:f5980. doi: 10.1136/bmj.f5980

8. DiBlasi RM. Nasal continuous positive airway pressure (CPAP) for the respiratory care of the newborn infant. Resp Care. (2009) 54:1209-35.

9. Briganti A, Melanie P, Portela D, Breghi G, Mama K. Continuous positive airway pressure administered via face mask in tranquilized dogs. J Vet Emerg Crit Care. (2010) 20:503-8. doi: 10.1111/j.1476-4431.2010.0 0579.x

10. MacFarlane PD, Mosing M. Early experience with continuous positive airway pressure (CPAP) in 5 horses - a case series. Can Vet J. (2012) 53:426-9.

11. Mosing M, Rysnik M, Bardell D, Cripps PJ, MacFarlane P. Use of continuous positive airway pressure (CPAP) to optimise oxygenation in anaesthetised horses-a clinical study. Equine Vet J. (2012) 45:414-8. doi: 10.1111/evj.12011

12. Staffieri F, Crovace A, De Monte V, Centonze P, Gigante G, Grasso S. Noninvasive continuous positive airway pressure delivered using a pediatric helmet in dogs recovering from general anesthesia. J Vet Emerg Crit Care. (2014) 24:578-85. doi: 10.1111/vec.12210

13. Raidal SL, McKean R, Ellul PA, Nielsen SG, Quinn CT. Effects of continuous positive airway pressure on respiratory function in sedated foals. J Vet Emerg Crit Care. (2019) 29:269-78. doi: 10.1111/vec.12816

14. Mosing M, MacFarlane P, Bardell D, Lüthi L, Cripps PJ, BettschartWolfensberger R. Continuous positive airway pressure (CPAP) decreases pulmonary shunt in anaesthetized horses. Vet Anaesth Analg. (2016) 43:61122. doi: $10.1111 /$ vaa. 12357 
15. Ramaswamy VV, More K, Roehr CC, Bandiya P, Nangia S. Efficacy of non-invasive respiratory support modes for primary respiratory support in preterm neonates with respiratory distress syndrome: systematic review and network meta-analysis. Pediatr Pulmonol. (2020) 55:2940-63. doi: 10.1002/ppul.25011

16. Rong ZH, Li WB, Liu W, Cai BH, Wang J, Yang M, et al. Nasal bi-level positive airway pressure (BiPAP) versus nasal continuous positive airway pressure (CPAP) in preterm infants $\leq 32$ weeks: a retrospective cohort study. J Pediatr Child Health. (2016) 52:493-8. doi: 10.1111/jpc.13175

17. Gupta D, Nath A, Agarwal R, Behera D. A prospective randomized controlled trial on the efficacy of noninvasive ventilation in severe acute asthma. Resp Care. (2010) 55:536-43.

18. Murphy PB, Rehal S, Arbane G, Bourke S, Calverley PMA, Crook AM, et al. Effect of home noninvasive ventilation with oxygen therapy vs. oxygen therapy alone on hospital readmission or death after an acute COPD exacerbation: a randomized clinical trial. J Am Med Assoc. (2017) 317:217786. doi: 10.1001/jama.2017.4451

19. Struik FM, Sprooten RT, Kerstjens HA, Bladder G, Zijnen M, Asin J, et al. Nocturnal non-invasive ventilation in COPD patients with prolonged hypercapnia after ventilatory support for acute respiratory failure: a randomised, controlled, parallel-group study. Thorax. (2014) 69:82634. doi: 10.1136/thoraxjnl-2014-205126

20. Blanch L, Fernández R, Benito S, Mancebo J, Net A. Effect of PEEP on the arterial minus end-tidal carbon dioxide gradient. Chest. (1987) 92:4514. doi: 10.1378/chest.92.3.451

21. Blanch L, Bernabe F, Lucangelo U. Measurement of air trapping, intrinsic positive end-expiratory pressure, and dynamic hyperinflation in mechanically ventilated patients. Resp Care. (2005) 50:110-23; discussion 123-4.

22. Koutsoukou A, Bekos B, Sotiropoulou C, Koulouris NG, Roussos C, MilicEmili J. Effects of positive end-expiratory pressure on gas exchange and expiratory flow limitation in adult respiratory distress syndrome. Crit Care Med. (2002) 30:1941-9. doi: 10.1097/00003246-200209000-00001

23. Puente-Maestu L, Stringer WW. Hyperinflation and its management in COPD. Int J Chron Obstruct Pulmon Dis. (2006) 1:381400. doi: 10.2147/copd.2006.1.4.381

24. Vieillard-Baron A, Jardin F. The issue of dynamic hyperinflation in acute respiratory distress syndrome patients. Eur Resp J, Supp. (2003) 42:437s. doi: 10.1183/09031936.03.00420703

25. Chakkarapani AA, Adappa R, Mohammad Ali SK, Gupta S, Soni NB, Chicoine $\mathrm{L}$, et al. Current concepts of mechanical ventilation in neonates - part 1: basics. Int J Pediatr Adolesc Med. (2020) 7:13-8. doi: 10.1016/j.ijpam.2020.03.003

26. Koterba AM, Wozniak JA, Kosch PC. Ventilatory and timing parameters in normal horses at rest up to age one year. Equine Vet J. (1995) 27:25764. doi: 10.1111/j.2042-3306.1995.tb03074.x

27. Yoder EA, Klann K, Strohl KP. Inspired oxygen concentrations during positive pressure therapy. Sleep Breath. (2004) 8:15. doi: 10.1007/s11325-004-0001-y

28. Mortola JP, Frappell PB, Dotta A, Matsuoka T, Fox G, Weeks S, et al. Ventilatory and metabolic responses to acute hyperoxia in newborns. Am Rev Respir Dis. (1992) 146:11-5. doi: 10.1164/ajrccm/146.1.11

29. Wong DM, Alcott CJ, Wang C, Hay-Kraus BL, Buchanan BR, Brockus CW. Physiologic effects of nasopharyngeal administration of supplemental oxygen at various flow rates in healthy neonatal foals. Am J Vet Res. (2010) 71:1081-8. doi: 10.2460/ajvr.71.9.1081

30. Morales-Quinteros L, Camprubí-Rimblas M, Bringué J, Bos LD, Schultz MJ, Artigas A. The role of hypercapnia in acute respiratory failure. Intensive Care Med Exp. (2019) 7(Suppl. 1):39. doi: 10.1186/s40635-019-0239-0

31. Vengust M. Hypercapnic respiratory acidosis: a protective or harmful strategy for critically ill newborn foals? Can J Vet Res. (2012) 76:275-80.

32. Ijland MM, Heunks LM, van der Hoeven JG. Bench-to-bedside review: hypercapnic acidosis in lung injury - from 'permissive' to 'therapeutic'. Crit Care. (2010) 14:137. doi: 10.1186/cc9238

33. Wong DM, Alcott CJ, Wang C, Bornkamp JL, Young JL, Sponseller BA. Agreement between arterial partial pressure of carbon dioxide and saturation of hemoglobin with oxygen values obtained by direct arterial blood measurements versus noninvasive methods in conscious healthy and ill foals. J Am Vet Med Assoc. (2011) 239:1341-7. doi: 10.2460/javma.239.10.1341

34. Batchelder PB, Raley DM. Maximizing the laboratory setting for testing devices and understanding statistical output in pulse oximetry. Anesth Analg. (2007) 105(Suppl. 6):S85-94. doi: 10.1213/01.ane.0000268495.35 207.ab

35. Giguere S, Sanchez LC, Shih A. Accuracy of calculated arterial saturation in oxygen in neonatal foals and effects of monitor, sensor, site of sensor placement, and degree of hypoxemia on the accuracy of pulse oximetry. J Vet Emerg Crit Care. (2014) 24:529-35. doi: 10.1111/vec.12231

36. Piquilloud L, Thevoz D, Jolliet P, Revelly JP. End-tidal carbon dioxide monitoring using a naso-buccal sensor is not appropriate to monitor capnia during non-invasive ventilation. Ann Intensive Care. (2015) 5:2. doi: 10.1186/s13613-014-0042-8

37. Mosing M, Auer U, MacFarlane P, Bardell D, Schramel JP, Bohm SH, et al. Regional ventilation distribution and dead space in anaesthetized horses treated with and without continuous positive airway pressure: novel insights by electrical impedance tomography and volumetric capnography. Vet Anaesth Analg. (2018) 45:31-40. doi: 10.1016/j.vaa.201 7.06.004

Conflict of Interest: The authors declare that the research was conducted in the absence of any commercial or financial relationships that could be construed as a potential conflict of interest.

Publisher's Note: All claims expressed in this article are solely those of the authors and do not necessarily represent those of their affiliated organizations, or those of the publisher, the editors and the reviewers. Any product that may be evaluated in this article, or claim that may be made by its manufacturer, is not guaranteed or endorsed by the publisher.

Copyright (C) 2021 Raidal, Catanchin, Burgmeestre and Quinn. This is an open-access article distributed under the terms of the Creative Commons Attribution License (CC $B Y)$. The use, distribution or reproduction in other forums is permitted, provided the original author(s) and the copyright owner(s) are credited and that the original publication in this journal is cited, in accordance with accepted academic practice. No use, distribution or reproduction is permitted which does not comply with these terms. 